University of Nebraska - Lincoln

DigitalCommons@University of Nebraska - Lincoln

USDA National Wildlife Research Center - Staff Publications
U.S. Department of Agriculture: Animal and Plant Health Inspection Service

January 2001

\title{
Estimation of Red-Winged Blackbird Mortality from Toxic Bait Application
}

James F. Glahn

Animal and Plant Health Inspection Service, National Wildlife Research Center, U.S. Department of Agriculture

Michael L. Avery

Animal and Plant Health Inspection Service, National Wildlife Research Center, U.S. Department of Agriculture, michael.I.avery@aphis.usda.gov

Follow this and additional works at: https://digitalcommons.unl.edu/icwdm_usdanwrc

Part of the Environmental Sciences Commons

Glahn, James F. and Avery, Michael L., "Estimation of Red-Winged Blackbird Mortality from Toxic Bait Application" (2001). USDA National Wildlife Research Center - Staff Publications. 587.

https://digitalcommons.unl.edu/icwdm_usdanwrc/587

This Article is brought to you for free and open access by the U.S. Department of Agriculture: Animal and Plant Health Inspection Service at DigitalCommons@University of Nebraska - Lincoln. It has been accepted for inclusion in USDA National Wildlife Research Center - Staff Publications by an authorized administrator of DigitalCommons@University of Nebraska - Lincoln. 
Published in Pesticides and Wildlife, edited by John J. Johnston. ACS Symposium Series 771. American Chemical Society, Washington, DC, 2001. 


\title{
Chapter 8
}

\section{Estimation of Red-Winged Blackbird Mortality from Toxic Bait Application}

\author{
James F. Glahn' ${ }^{1}$ and Michael L. Avery ${ }^{2,3}$ \\ ${ }^{1}$ Animal and Plant Health Inspection Service, National Wildlife Research \\ Center, U.S. Department of Agriculture, Mississippi Field Station, \\ P.O. Drawer 6099, Mississippi State, MS 39762-6099 \\ 'Animal and Plant Health Inspection Service, National Wildlife Research \\ Center, U.S. Department of Agriculture, Florida Field Station, \\ 2820 East University Avenue, Gainesville, FL 32641
}

\begin{abstract}
Application of slow-acting toxic bait is one method of reducing local populations of depredating blackbirds. Estimating numbers of birds killed in such baiting operations is difficult because affected birds die off-site and are seldom recovered. We conducted bioassays and flight pen studies of red-winged blackbirds (Agelaius phoeniceus) with a slow-acting, toxic brown rice bait to determine whether bird mortality could be predicted accurately using the Poisson and binomial discrete probability distributions. Bioassays confirmed that brown rice treated with $2 \%(\mathrm{w} / \mathrm{w}) 2$-chloro-p-acetotoluidide was effective as a 1-particle lethal bait for redwings. Within a 0.2-ha flight pen, we offered this bait diluted 1:99 with untreated particles to three 60-bird flocks and three 20-bird flocks in a simulated baiting operation. Across the 6 test groups, we recorded bird mortality not different from that predicted using the Poisson distribution. We obtained the same estimates using the binomial distribution. Although a number of factors could influence the relevance of our findings to field use, the application of discrete probability distributions appears superior to using estimates of bait consumption as a means for evaluating blackbird mortality due to slow-acting toxic baits.
\end{abstract}

\section{Introduction}

For a number of years, reduction of winter blackbird populations in Louisiana and Texas with toxic bait has been a key component of integrated management strategies for reducing damage to cultivated rice (1). Although there are no objective data documenting increased rice crop yields following toxic baiting of blackbirds, surveys of rice producers support the overall effectiveness of this technique $(l)$. There is currently

${ }^{3}$ Corresponding author: e-mail: Michael.L.Avery@usda.gov. 
a Federal section 3 registration for the use of the toxin DRC-1339 (3-chloro-p-toluidine hydrochloride) to bait blackbirds at pre-roost staging areas (EPA registration number 56228-30). Most baiting to date has been conducted in Louisiana and Texas, but plans are under discussion to extend blackbird baiting programs to other areas (2).

Development of blackbird baiting techniques has focused on slow-acting toxicants such as DRC-1339 and closely related compounds such as 2-chloro-p-acetotoluidide (CAT). These compounds are attractive as blackbird toxicants because of their high toxicity to blackbirds and starlings but low toxicity to most mammals and predatory birds (3). The mode of action of these compounds is not well-understood, but death appears to result from nephrotoxicity (4). Time to death can extend to several days following ingestion.

Despite the potential utility of DRC-1339 and CAT for reducing local blackbird numbers, accurate determination of the impacts of baiting operations on target species populations is not straightforward because most poisoned birds die far from the bait site. This precludes direct counts of dead birds as an evaluation option. Alternatively, bait consumption has been used most often to estimate the number of blackbirds killed in baiting trials with CAT and DRC-1339 $(5,6,7,8,9)$. These mortality estimates in field operations have relied upon consumption and mortality estimates from laboratory trials (10) or extrapolations from the theoretical number of treated particles taken per unit weight of bait consumed by birds. Independent verification of the validity of these approaches is lacking ( 1 ).

One potentially useful option not previously considered is application of discrete probability function distributions to predict mortality. Use of the binomial or the Poisson distribution is relevant because (1) in blackbird baiting operations, a single treated bait is formulated to be lethal, and (2) treated baits are presented in a mixture diluted with untreated baits. For a given bait dilution, it is straightforward to apply either function to calculate the proportion of birds that ate zero treated baits. All other blackbirds then consumed $\geq 1$ treated bait and died. The only additional information needed to apply these functions is the mean number of total baits consumed by individual birds on the bait site.

We are unaware of any attempt to estimate blackbird mortality using this approach or to compare the accuracy of estimates obtained with theses functions with those derived from bait consumption. Thus, we conducted feeding trials to: (1) establish the lethality of a single treated bait, (2) establish an appropriate dilution of untreated to treated bait, (3) document feeding behavior of blackbird flocks on simulated bait sites, (4) predict mortality using binomial and Poisson distributions and bait consumption estimates, and (5) compare the mortality estimates to the actual number of birds killed.

The study took place during October-November 1987 when both CAT and DRC1339 were being considered for registration as blackbird toxicants. Eventually, DRC1339, not CAT, was registered. Nevertheless, because the two compounds are very similar in their effects on blackbirds (4), our findings are applicable to current blackbird baiting programs with DRC-1339 or to any other slow-acting bait formulated to deliver a single-particle lethal dose.

\section{Methods}

\section{Test Birds}

All test birds were male red-winged blackbirds trapped in the vicinity of Gainesville, Florida and held in captivity for at least 2 weeks at the Florida Field Station of the U.S. Department of Agriculture's National Wildlife Research Center. We maintained birds in group holding cages $(1.2 \times 1.2 \times 1.8-\mathrm{m})$ in a covered outdoor aviary and allowed them free access to commercial game bird diet and water.

\section{Bioassay}

Three days before testing, we removed 10 birds from their communal holding cage and placed them individually in $46 \times 46 \times 91-\mathrm{cm}$ cages in a covered outdoor aviary. Except during bait presentation, test birds had unlimited access to medium grain brown rice and water. The bait used in all testing was a medium grain brown rice bait formulated at the National Wildlife Research Center to contain 2\% (w/w) CAT using $1 \%$ Alcolec $S$ as a sticker.

On the treatment day, we fasted test birds for approximately $5 \mathrm{~h}$, and then gave 5 randomly selected birds 1 treated bait mixed with 4 untreated rice baits in their feed cups. The other birds received 5 untreated brown rice grains. During the 4-h bait presentation, we covered the bottom of each cage with a shallow aluminum tray to reduce the possibility of bait loss. After baits had been eaten, birds again received untreated rice for $48 \mathrm{~h}$. Dead birds were necropsied; survivors were released.

\section{Flight Pen Trials, Untreated Bait}

Within a $46 \times 46-\mathrm{m}$ flight pen at the Florida Field Station, we tilled and smoothed eight $9 \times 12-\mathrm{m}$ bait plots. As needed, we covered each baited plot with black polyethylene plastic sheeting to prevent birds or rain from reaching the bait. A $3 \times 10$ $x$ 2-m drop-in decoy trap located in one corner of the flight pen served to hold and to recapture groups of test birds. In this trial, and in the one with treated bait, we allowed birds access to the baited plot only in the morning and late afternoon to simulate morning and evening activity at staging area bait sites in the field.

This set of trials involved two 20-bird groups and two 60-bird groups. One day before testing, we removed birds from their holding cages, placed the test group in the decoy trap, and provided brown rice and water. We individually identified 15 randomly selected birds in each group with $1.9 \times 6.4-\mathrm{cm}$ plastic tail tags inscribed with unique letter-number codes and attached to the base of the tail feathers with hot-melt glue. After the birds fasted overnight in the decoy trap, we released them into the flight pen between 0730 and 0800 to forage on a $9 \times 12-\mathrm{m}$ plot hand-broadcast with untreated brown rice at a rate of $28 \mathrm{~kg} / \mathrm{ha}(300 \mathrm{~g} / \mathrm{plot})$.

Two observers with binoculars and spotting scopes watched from an observation blind at the north end of the flight pen to quantify foraging behavior of birds using the 
baited plot. We recorded latency to use of the baited plot, lengths of flock feeding bouts, and the number of rice grains consumed by individually marked birds during 1 min observation periods. We defined a flock feeding bout as starting when more than half of the birds in the test group were foraging on the plot and ending when all birds left the plot and failed to return within 5-min. After morning observations, birds were allowed to return to the decoy trap for food and water. Later the same day, test birds fasted for $2 \mathrm{~h}$ and we again released them into the flight pen at approximately 1500 to forage on the same plot. We recorded foraging behavior as before.

\section{Flight Pen Trials, Treated Bait}

The trials involved 3 test groups of 20 male redwings and 3 test groups of 60 male redwings each. We tested each group separately in the flight pen following the same procedures used with untreated bait. The $9 \times 12-\mathrm{m}$ test plots held $300 \mathrm{~g}$ bait/plot, with CAT-treated brown rice diluted 1:99 ( $3 \mathrm{~g}$ treated and $297 \mathrm{~g}$ untreated).

When the morning feeding bout ended, observers entered the flight pen, covered the baited plot with plastic sheeting, and opened the decoy trap to allow birds to return to the trap for food and water. Birds then fasted for $2 \mathrm{~h}$ and we released them again at 1500 . We recorded behavior using the same procedure as the morning trial. Following the afternoon feeding activity, we retrapped birds from the test group and searched the flight pen for dead birds. We maintained the test group on brown rice and water for 7 days to assess mortality. We released survivors and necropsied half of the dead birds in each test group to confirm that death was due to CAT poisoning.

We assessed bait consumption from each $9 \times 12-\mathrm{m}$ test plot by establishing 10 ( 3 test groups) or 25 ( 3 test groups) randomly located $0.09-\mathrm{m}^{2}$ sampling quadrats. We marked the corners of each quadrat with small wooden sticks and set the number of rice baits in each at 12 . We recounted the baits on sampling quadrats after exposure to foraging birds. To estimate the mass of treated bait consumed by birds in the test group, we multiplied the overall reduction in mass by the proportion of treated bait applied ( 1 in 100). We then divided by $19 \mathrm{mg} / \mathrm{bait}$ to yield an estimate of number of treated baits consumed by the test group.

\section{Estimation with Binomial and Poisson}

We used mean rates of individual bait consumption from birds in each test group to generate mortality predictions from the probability functions. For the binomial distribution, the basic function is $(\mathbf{p}+\mathbf{q})^{\mathbf{n}}$, where $\mathrm{p}$ is the proportion of treated baits offered (also termed the bait dilution rate), $q(=1-p)$ is the proportion of untreated baits offered, and $n$ is the mean number of total baits (treated and untreated) eaten per bird. In expanding the binomial function, the term $\mathbf{q}^{\mathbf{n}}$ is the only one of interest as it represents the proportion of birds that ate no treated bait; all other birds ate at least one and died. The proportion that died is thus $\mathbf{1}-\mathbf{q}^{\mathbf{n}}$.

The Poisson distribution is represented by the function, $\mathbf{P}(\mathbf{x})=(\mathbf{n p})^{\mathbf{x}} /\left(\mathbf{x} ! \mathrm{e}^{\mathrm{np}}\right)$, where $\mathrm{e}=2.7183, \mathrm{n}=$ mean total number of baits eaten/bird, $\mathrm{p}=$ the bait dilution, and $x=$ mean number of treated baits eaten/bird. When $x=0$, that is when no toxic bait is taken, the expression reduces to $\mathbf{P}(\mathbf{0})=\mathrm{e}^{-\mathrm{np}}$. Thus, $\mathrm{P}(0)$ represents the proportion of the flock that did not consume a toxic bait, and 1-P (0) is the proportion of the flock expected to die from eating at least 1 treated bait.

We applied Chi-square goodness of fit tests to examine whether observed mortality from baiting trials differed from that predicted using the binomial and the Poisson distribution functions.

\section{Results}

\section{Bioassay}

Each of the 4 birds that ate treated bait died within $48 \mathrm{~h}$. One bird that was offered treated bait ate nothing. Birds that received only untreated bait survived. Necropsied birds all exhibited signs typical of CAT poisoning (11): separated gizzard linings, mottled livers and kidneys, and deposition of urates on internal surfaces, particularly the pericardium.

\section{Flight Pen Trials, Untreated Bait}

Flock foraging bouts averaged $4.5 \mathrm{~min}(\mathrm{SE}=0.6, n=10)$ and individual feeding rates averaged 23.9 seeds/min $(S E=1.5, n=44)$. The product of these two values, 108 seeds/bout, is an estimate of the individual bait consumption during a daily feeding bout. Based on this, for trials with treated bait, we used a dilution of 1 treated bait per 100 total baits because we intended for a blackbird to obtain only 1 treated bait during a typical daily feeding bout.

\section{Flight Pen Trials, Treated Bait}

The latency to start of feeding in the baited plot varied from about $10 \mathrm{sec}$ to over 17 min following release from the decoy trap. Estimated total bait consumption varied among the 6 test flocks from 9.2\% (SE $=9.2 \%$ ) to 74.7\% ( $\mathrm{SE}=7.8$ ) (Table I). Generally, the 60-bird groups fed longer, removed more bait, and had higher estimated individual rates of treated bait consumption than did the 20-bird flocks. The morning foraging bouts tended to be longer than those in the afternoon, but the birds readily fed on the treated bait site the second time.

As suggested by bait consumption estimates, mortality in the 60-bird groups $(\bar{x}=$ $78 \%$ ) exceeded that in the 20-bird groups $(68 \%)$. For all groups, approximately $92 \%$ of the eventual mortality occurred within $48 \mathrm{~h}$ of initial exposure to the treated bait (Fig. 1). No deaths occurred beyond $96 \mathrm{~h}$ following exposure. Post-mortem examination of 90 of the 181 dead test birds revealed signs typical of CAT poisoning (11) in each case. 


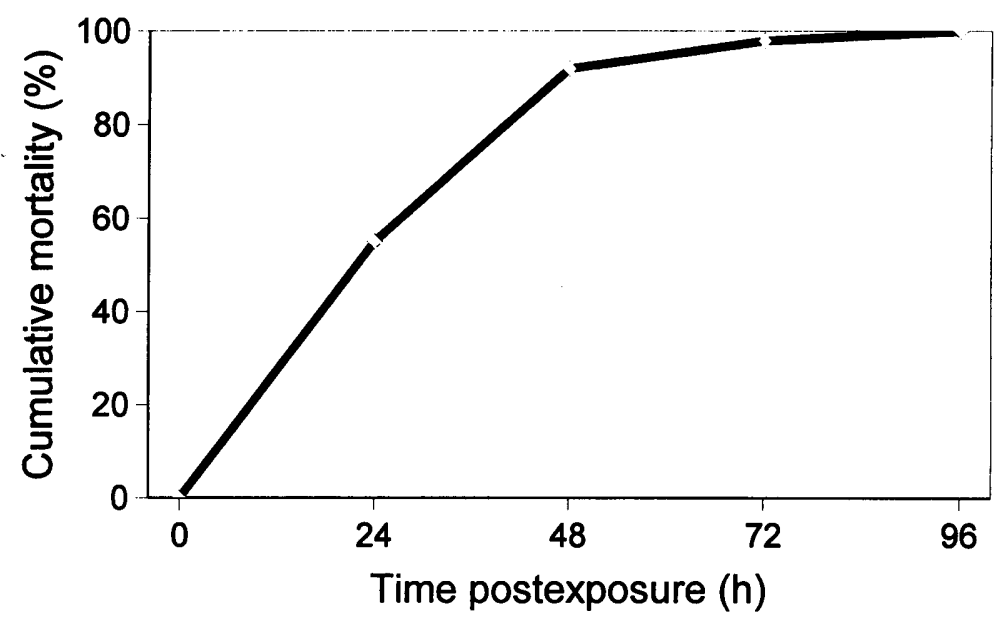

Figure 1. Cumulative mortality among three 20-bird and three 60-bird red-winged blackbird flocks following exposure to brown rice bait treated with $2 \%(g / g) C A T, a$ slow-acting toxicant.

\section{Morality Estimation}

Chi-square goodness of fit tests showed no difference $(P=0.39)$ between observed mortality and that predicted from the binomial and Poisson distributions (Table I). Only in group 6 did the observed mortality differ substantially from the predicted mortality. In contrast, estimates of treated bait consumption consistently exceeded observed mortality, particularly in the 60-bird groups (Table I). If we assumed 1 treated bait represented 1 dead bird, then mortality based on bait consumption would be greatly overestimated.

Table I. Bait consumption and mortality among groups of red-winged blackbirds during baiting trials in a 0.2-ha flight pen, Gainesville, FL. Each group of birds was exposed to $300 \mathrm{~g}$ of brown rice bait, $3 \mathrm{~g}$ of which was treated with $2 \%(\mathrm{~g} / \mathrm{g})$ CAT, a slow-acting toxin.

\begin{tabular}{|c|c|c|c|c|c|c|c|c|}
\hline \multirow{2}{*}{$\begin{array}{l}\text { Test } \\
\text { group }\end{array}$} & \multirow{2}{*}{$\begin{array}{l}\text { Number } \\
\text { of birds }\end{array}$} & \multicolumn{2}{|c|}{$\begin{array}{l}\% \text { total bait } \\
\text { consumption }\end{array}$} & \multicolumn{2}{|c|}{$\underline{\text { Baits removed }}^{l}$} & \multicolumn{3}{|c|}{ Dead birds } \\
\hline & & $\overline{\bar{x}}$ & $\overline{S E}$ & Total & $\overline{\text { Per bird }}$ & $\overline{\text { Actual }}$ & Binomial $^{2}$ & $\overline{\text { Poisson }^{2}}$ \\
\hline 1 & 20 & 9.2 & 9.2 & 1453 & 73 & 10 & 10.4 & 10.4 \\
\hline 2 & 60 & 50.8 & 10.8 & 8021 & 134 & 44 & 44.4 & 44.4 \\
\hline 3 & 20 & 16.3 & 3.7 & 2574 & 129 & 13 & 14.5 & 14.4 \\
\hline 4 & 60 & 71.7 & 12.5 & 11321 & 188 & 45 & 50.9 & 51.0 \\
\hline 5 & 60 & 74.7 & 7.8 & 11794 & 197 & 51 & 51.7 & 51.6 \\
\hline 6 & 20 & 10.3 & 24.2 & 1626 & 81 & 18 & 11.1 & 11.2 \\
\hline
\end{tabular}

1 - Total bait removal is calculated by multiplying $300 \mathrm{~g}$ by the $\%$ total bait consumption and dividing by $0.019 \mathrm{~g} / \mathrm{bait}$. Then divide by the number of birds to get bait consumption per bird (n).

- Predicted from binomial and Poisson distribution functions. There was no difference $(P>$ $0.5)$ between predicted and actual mortality for either distribution $\left(X^{2}=5.23,5 \mathrm{df}\right)$.

\section{Discussion}

In order to evaluate the effectiveness of applying toxic bait for blackbird control, reliable estimates of mortality due to such management programs are needed. Reliable mortality estimates are also needed for the development of realistic environmental 
assessments and for incorporation into blackbird population models that will help determine long-term management strategies. Attempts to estimate mortality from consumption of single-particle lethal bait are hampered by not knowing how many treated baits are taken per bird. As illustrated in our study, inaccurate and unrealistic overestimates of mortality arise if each treated bait removed is assumed to represent one dead bird. Such an approach will yield an estimate of the maximum possible number killed which could have utility by putting an upper bound on baiting mortality (1). It is unlikely, however, that this type of estimate will accurately reflect mortality because at least some individuals actually ingest $>1$ treated bait. In our study, the latter proved to be the case, as the estimated ingestion of treated bait among the 6 test groups ranged from 0.9 to 2.5 baits per dead bird. Empirical verification of multiple treated bait ingestion in field studies would be difficult to accomplish

Given the possibility that blackbirds ingest $>1$ treated bait, but given the difficulty in documenting this, then determining mortality using bait consumption estimates reduces to guesswork. The best that can be done is to calculate a range of mortality estimates assuming different levels of bait consumption per bird $(l)$.

The use of discrete probability distributions offers an alternative that is independent of estimates of total bait consumption. In our flight pen trial, both the Poisson and the binomial distributions yielded predictions very similar to the actual mortality from bait consumption. Assumptions inherent in the use of the Poisson distribution are: (1) the amount of bait distributed is large relative to the amount eaten, (2) the treated and untreated baits are evenly mixed, and (3) birds do not distinguish between treated and untreated baits. Assumption (1) does not apply to the binomial distribution, so the binomial might be preferable to the Poisson for that reason. The only data needed to calculate mortality estimates from the binomial or the Poisson distribution are numbers of baits eaten by individual blackbirds during feeding bouts on the bait site. These observations might be difficult to make, but it is certainly reasonable to do so because the result will be more reliable projections of the impact of toxic baiting on blackbird populations.

The relevance of our findings to field situations depends on the extent to which the flight pen foraging conditions resembled foraging conditions in the field. At this point, we have no field data on individual or flock foraging bout lengths at bait sites, so we cannot compare our experimental results to the birds' behavior under field conditions. We observed nothing to indicate that the test birds' feeding activity in the flight pen was abnormal. The birds readily adjusted to the flight pen environment and were not reluctant to feed from the baited plot. Another question concerns the relatively small flock sizes and sex of redwings tested. Blackbird foraging flocks often number in the thousands and at certain times are dominated by female redwings or other blackbird species (12). Because of differences between this study and field conditions in size and composition of blackbird flocks, there remains some question as to the applicability of our results to the field situation. Clearly, more detailed in-depth study of blackbird behavior at bait sites is needed.

\section{Management Implications}

If toxic baiting continues to be an important component of blackbird control strategies, then the accurate mortality predictions made in this study using the binomial and Poisson distributions should be of interest. Accurate mortality projections can be made and insights can be gained that might assist in designing baiting programs to meet specific objectives. For example, if mortality is to be maximized in a program using single lethal dose baits, and if multiple toxic bait ingestion is irrelevant, then for an average consumption (n) of 100 baits/bird, a dilution of 1 toxic bait/20 total baits (i.e. $q=0.95)$ would result in virtually $100 \%$ mortality $\left(1-q^{n}=0.994\right.$, or $99.4 \%$ mortality). However, based on the overall $75 \%$ mortality of birds foraging on bait in this study, we believe the 1:99 dilution is practical for achieving efficacious blackbird control and also for reducing nontarget hazards in the field. Allowing some individuals to survive exposure to bait may actually increase overall efficacy because these birds may likely return to the bait site and serve to decoy in other birds on subsequent days of baiting.

The average bait consumption per bird (n) will have to be obtained empirically during the pre-baiting period through close observation of feeding behavior on the bai site. The feeding bouts of as many birds as possible should be recorded to maximize the confidence in the estimate of feeding bout length. This value is then used with the dilution rate in either the binomial or the Poisson distribution to calculate the proportion of birds killed. A projection of the absolute number of dead birds requires an estimate of the total population using the bait site. This can only be obtained through careful, consistent monitoring of the bait site.

\section{Acknowledgments}

P. W. Lefebvre, R. E. Matteson, and C. O. Nelms assisted with various aspects of the study. We thank J. F. Heisterberg, C. E. Knittle, and A. R. Stickley for reviewing earlier drafts of this paper. D. T. Bohdanowicz assisted with preparation of the manuscript.

\section{References}

1. Glahn, J. F.; Wilson, E. A. Proc. East. Wildl. Damage Control Conf. 1992, 5, 117 123.

2. Avery, M. L.; Kenyon, M. J.; Linz, G. M.; Bergman, D. L.; Decker, D. G.; Humphrey, J. S. J. Wildl. Manage. 1998, 62, 388-394. 
3. DeCino, T. J.; Cunningham, D. J.; Schafer, E. W., Jr. J. Wildl. Manage. 1966, 30, 249-253.

4. Schafer, E. W., Jr. In CRC Handbook of Pest Management in Agriculture; Pimentel, D., Ed.; Boca Raton, FL, 1991. Vol. II., pp 599-610.

5. Besser, J. F.; Bray, O. E. Bird Damage Research Report 45. U. S. Fish Wildl. Serv., Denver Wildl. Res. Cen. 1977.

6. Knittle, C. E.; Guarino, J. L.; Nelson P. C. Proc. Vertebr. Pest Conf. 1980, 9, 3137.

7. Glahn, J. F.; Heisterberg, J. F. Bird Damage Research Report 198. U. S. Fish Wildl. Serv., Denver Wildl. Res. Cen. 1981.

8. Cummings, J. L.; Schafer, E.W., Jr.; Cunningham, D. J. Bird Damage Research Report 344. U. S. Fish Wildl. Serv., Denver Wildl. Res. Cen. 1985.

9. Cummings, J. L.; Schafer, E. W., Jr. Bird Damage Research Report 357. U. S. Fish Wildl. Serv., Denver Wildl. Res. Cen. 1985.

10. Schafer, E. W., Jr.; Brunton, R. B.; Schafer E. C.; Chavez, G. Bird Damage Research Report 93. U. S. Fish Wildl. Serv., Denver Wildl. Res. Cen. 1978.

11. Lefebvre, P. W.; Matteson, R. E.; Decker, D. G.; Hillman, C. D.; Palmer, J. E. Bird Damage Research Report 73 . U. S. Fish Wildl. Serv., Denver Wildl. Res. Cen. 1978.

12. Labisky, R. F.; Brugger,K. E. Technical Report 36. U. S. Fish Wildl. Serv., Florida Cooperative Fish Wildl. Res. Unit. 1989. 